\title{
Case Report Variability in Clinical Presentation of Neonatal Stroke: Report of Four Cases
}

\author{
Sonia Joseph, Dimitrios Angelis, Robert Bennett, Bhargavi Kola, and Amanda Hughes
}

Texas Tech University Health Sciences Center, Odessa, TX, USA

Correspondence should be addressed to Dimitrios Angelis; dimitrios.angelis@ttuhsc.edu

Received 11 October 2016; Accepted 12 December 2016; Published 17 January 2017

Academic Editor: Isabella Laura Simone

Copyright (C) 2017 Sonia Joseph et al. This is an open access article distributed under the Creative Commons Attribution License, which permits unrestricted use, distribution, and reproduction in any medium, provided the original work is properly cited.

Neonatal stroke can be a cause of long term neurodevelopmental disability, seizures, and impaired cognitive function. We present four cases of neonatal stroke, associated with different risk factors and clinical presentations. Two of these newborns were born to mothers with no prenatal care.

\section{Introduction}

Neonatal stroke is an important complication to consider when assessing a newborn as it has the potential for chronic sequelae related to neurodevelopment. Injury to cerebral tissue occurs by a disruption in arterial blood flow either from a thrombus or embolism, also known as PAIS, or from an interruption by a thrombus in a major cerebral vein, otherwise known as CSVT. Here, we present four consecutive cases of neonatal stroke over a period of two years, associated with different risk factors and different clinical presentations. Two of these babies were born to mothers with no prenatal care.

\section{Cases}

A 1700-gram preterm female infant was born at 33 weeks' gestation to a primigravida mother with no prenatal care and unknown GBS status admitted with severe preeclampsia. Prolonged fetal heart rate decelerations resulted in an emergent C-section. At birth, the patient was hypotonic with an acidotic cord blood gas $(\mathrm{pH}=7)$. She required mechanical ventilation and cardiovascular support. An echocardiogram demonstrated no intracardiac thrombi and a HUS was normal. There was an interim gradual neurologic improvement. An MRI, done at about two weeks of life, showed a thrombus in the right transverse and straight sinuses consistent with CSVT. A repeat MRI a week later was stable (Figures 1(a1) and 1(a2)). The patient was discharged home on LMWH. No coagulation defect was identified in this case. The placental pathology showed the presence of an infarct.

A 3400-gram male infant was delivered to a healthy mother with no prenatal care and an unknown GBS status at 37.4 weeks' gestation. The infant developed respiratory failure with bradycardia requiring intensive resuscitative measures (chest compression and intubation) and was admitted to the intensive care unit where he continued to have systemic compromise needing inotropes, mechanical ventilation, and blood products. On day of life one, the patient was noted to have abnormal posturing, but an EEG and HUS were negative. He developed a brief period of hyperthermia which was managed conservatively. An MRI showed abnormal signal intensity in the lower superior sagittal and bilateral transverse sinuses, indicating CSVT (Figures 1(b1) and 1(b2)). No placenta pathology was available for this patient. Following evaluation at a tertiary center, the coagulation work-up was negative.

A 2600-gram male infant was born at 39-week gestation to a healthy mother with unremarkable prenatal labs and negative GBS status. The mother presented with spontaneous ROM with clear amniotic fluid minutes before an uncomplicated vaginal delivery. Following delivery, the infant showed signs of feeding intolerance with emesis and shallow breathing. At about 10 hours of life, he proceeded to have seizure activity lasting about 10 minutes. Laboratory evaluation was significant for hypocalcemia, hypoglycemia, 


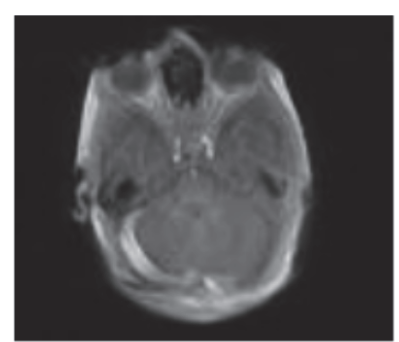

(a1)

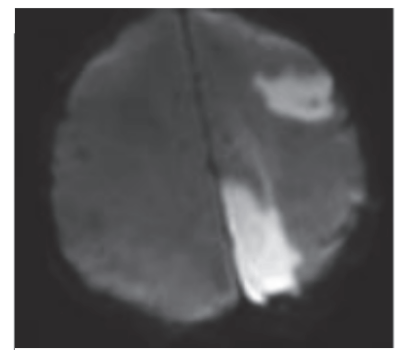

(c1)

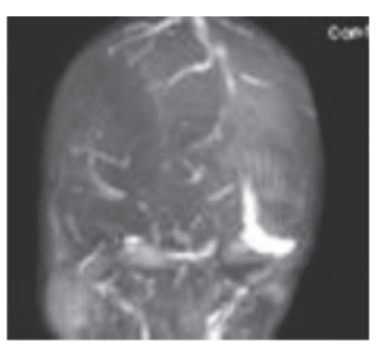

(a2)

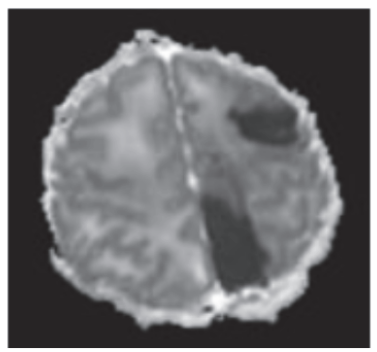

(c2)

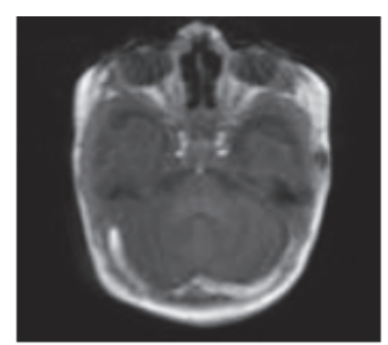

(b1)

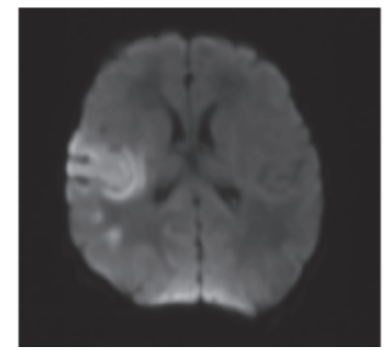

(d1)

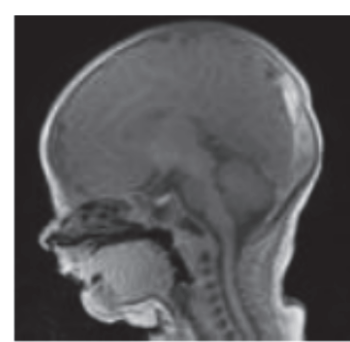

(b2)

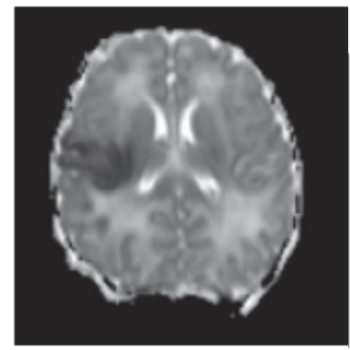

(d2)

FIgURE 1: (a1, a2) Preterm neonate with severe perinatal depression born to mother with no prenatal care: the MRI and MRV images, respectively, show venous sinus thrombosis involving the entire right transverse and sigmoid sinus, most of the straight sinus, and the medial aspect of the left transverse sinus. In this case low molecular weight heparin was initiated. (b1, b2) Term neonate with sepsis, hyperthermia, and suspected episodes of seizures. On T1 images there was an abnormal signal intensity in the lower superior sagittal sinuses as well as bilateral transverse sinuses, consistent with CSVT. A small amount of intraventricular hemorrhage in the posterior body and atrium of the right lateral ventricle was also identified. Infant's coagulation work-up was negative for any major clotting disorder. (c1, c2) Diffusion weighted images (DWI) as well as ADC Map are shown for a term neonate with no identified risk factors that presented with seizures. (d1, d2) An IUGR infant admitted to the NICU due to suspected apnea and respiratory distress. An MRI without contrast demonstrated a moderately sized acute cortical infarct in the right middle cerebral artery territory, involving the right posterior frontal lobe and frontoparietal junction at the region of the motor strip.

and thrombocytopenia. An MRI showed evidence of an acute multifocal stroke involving the left posterior, medial parietal, and left occipital lobe (Figures $1(\mathrm{cl})$ and 1(c2)). $\mathrm{CT}$ of the brain was negative. The patient was followed conservatively. Placenta was not evaluated in this case. The $\mathrm{KB}$ test was positive revealing a mild to moderate fetalmaternal hemorrhage.

A 1970-gram male infant, with IUGR, was born at 38 weeks' gestation to a GBS negative mother with a history of diabetes mellitus type 2 and smoking. The mother developed preeclampsia. Shortly after birth, he experienced episodes of desaturation. CXR was within normal limits. Subsequently, he developed two episodes of suspected central apnea, requiring stimulation. CT scan and HUS were negative. However, an MRI without contrast demonstrated an acute cortical infarct in the right MCA, involving the posterior frontal lobe and frontoparietal junction (Figures 1(d1) and 1(d2)). Further neurological and hematological evaluation failed to demonstrate any significant defect. Conservative management was followed for this patient. Placental pathology was consistent with acute infection as well as a small placental infarct.

\section{Discussion}

Perinatal stroke is defined as a cerebrovascular accident occurring between 20 weeks' gestation and up to 28 days after birth in the newborn period, causing neurological damage in the territory of the affected vessel and persisting for greater than 24 hours [1]. The classification includes perinatal arterial ischemic strokes (PAIS), cerebral sinus venous thrombosis (CSVT), or hemorrhagic strokes. PAIS is reported in 1 in 2300-4000 deliveries as compared to the rarer CSVT which occurs between 1 and 2.69 per 100,000 births. CSVT occurs when venous blood flow in a major sinus becomes disrupted. About $60 \%$ of reported CSVT cases involve a parenchymal infarction [2].

Our cases demonstrate the variability of the clinical presentation of neonatal stroke. Nonspecific neurologic signs and symptoms (such as respiratory failure, temperature instability) along with the typical neurologic symptoms (seizures, abnormal posturing) could denote a disruption in supply or demand of oxygen in the vulnerable neonatal brain. Seizures are the presenting symptom for newborns with stroke in the first month of life, accounting for $70-90 \%$ of these cases [3]. Only $50 \%$ of newborns present with typical focal seizures and up to $20 \%$ of these events are subtle and difficult to recognize [4]. A high index of suspicion is required for newborns born to mothers with specific risk factors, presenting with subtle neurologic signs.

PNC is a well-established and effective way to monitor maternal and fetal health and identify women at risk for unfavorable birth outcomes [5]. Early and continuous PNC helps the delivery of an array of medical, nutritional, and educational interventions at different stages of pregnancy [6]. 
TABLE 1

\begin{tabular}{|c|c|c|c|c|}
\hline & Case 1 & Case 2 & Case 3 & Case 4 \\
\hline Gestational age & 33 weeks & 37.4 weeks & 39 weeks & 38 weeks \\
\hline Presence of prenatal care & None & None & Yes & Yes \\
\hline $\begin{array}{l}\text { Risk factors associated } \\
\text { with stroke }\end{array}$ & $\begin{array}{l}\text { Preeclampsia, } \\
\text { primiparity }\end{array}$ & Resuscitation at birth & None & $\begin{array}{c}\text { Preeclampsia, } \\
\text { IUGR, } \\
\text { smoking, obesity } \\
\text { H/o diabetes mellitus } \\
\text { type } 2 \text { (normal GTT) }\end{array}$ \\
\hline Presenting symptoms & $\begin{array}{l}\text { Hypotonia, } \\
\text { respiratory distress }\end{array}$ & $\begin{array}{l}\text { Central apnea, } \\
\text { hyperthermia, } \\
\text { respiratory distress }\end{array}$ & Seizures & $\begin{array}{l}\text { Central apnea, } \\
\text { respiratory distress }\end{array}$ \\
\hline $\begin{array}{l}\text { APGAR score at } 1,5, \\
10 \mathrm{~min}\end{array}$ & $1,5,8$ & $8,1,7$ & $8,9,9$ & $8,9,9$ \\
\hline Clinical course & $\begin{array}{l}\text { Receiving prolonged } \\
\text { mechanical ventilation } \\
\text { Requiring inotropes and } \\
\text { blood products } \\
\text { Clinical recovery }\end{array}$ & $\begin{array}{l}\text { Requiring prolonged } \\
\text { mechanical ventilation, } \\
\text { Receiving inotropes, } \\
\text { transfusions of FFP, } \\
\text { packed RBCs } \\
\text { Clinical recovery }\end{array}$ & $\begin{array}{c}\text { Seizure activity } \\
\text { controlled with AED } \\
\text { Requiring high GIR and } \\
\text { calcium gluconate } \\
\text { supplements } \\
\text { Clinical recovery } \\
\end{array}$ & $\begin{array}{l}\text { Mild oxygen } \\
\text { requirements } \\
\text { Clinical recovery }\end{array}$ \\
\hline Placental pathology & Placental infarct & Not performed & $\begin{array}{l}\text { Not performed } \\
\quad+\text { KB test }\end{array}$ & $\begin{array}{c}\text { Acute funisitis, acute } \\
\text { chorioamnionitis, } \\
\text { placental infarct }\end{array}$ \\
\hline Coagulation work-up & Negative & Negative & Negative & Negative \\
\hline Follow-up of the patient & Anticoagulation & $\begin{array}{l}\text { Conservative } \\
\text { management }\end{array}$ & $\begin{array}{l}\text { Conservative } \\
\text { management }\end{array}$ & $\begin{array}{l}\text { Conservative } \\
\text { management }\end{array}$ \\
\hline
\end{tabular}

Despite recommendations, a proportion of women continue to receive insufficient or no PNC [6]. Absence of prenatal has many reasons including socioeconomic variable and racial differences. A retrospective cohort study found that about one in five women had less than adequate PNC with striking racial differences [7]. In our cases two of the four mothers, all with CSVT, had no prenatal care. Due to the rarity of neonatal stroke and the small number of cases it would be difficult to speculate any association between absence of prenatal care, socioeconomic factors, and neonatal stroke and further studies are required.

In Table 1 we summarize the known risk factors associated with neonatal stroke, in these cases. Preeclampsia, the presenting symptom in 2 of our cases, is a hypercoagulable status in the fetus and is associated with decreased placental blood flow. In a case-control study, which included 40 newborns with stroke it was found that preeclampsia, chorioamnionitis, PROM, and infertility were independently associated with PAIS [8]. The investigators concluded that perinatal risk factors could act synergistically. PNC was not adequately assessed and socioeconomic factors and social habits were not reported. Only 3 of these 40 cases had a documented placental pathology report. In our study 2 patients had a placental infarct seen at the pathology report. Placental infarction and inflammatory changes have been reported in patients with cerebral palsy, but not in patients with stroke and hence it is difficult to interpret their significance [9]. Similar associations regarding the presence or absence of specific risk factors have been described for CSVT [10].
Interestingly, primiparity is an important risk factor for PAIS in term gestations, but this association appears to be weak in preterm infants and in those with CSVT $[11,12]$.

MRI is considered the study of choice for identifying and diagnosing perinatal stroke in term babies. Perinatal stroke occurs mainly in full-term infants and in lower incidence in preterm infants [13]. PAIS is more common on the left side, in both term and preterm newborns, and usually follows the distribution of the MCA. In preterm babies due to the involvement of several MCA lenticulostriate branches, serial HUS might be more sensitive than early MRI for identification of a type of stroke that is common in this age group. Plaisier et al. following a specific protocol of serial HUS found that MRI was superior in identifying cerebellar hemorrhage but serial ultrasonography in detection of IVH, perforator stroke, and CSVT [14]. In preterm newborns, CSVT typically should be considered when there is bilateral white matter involvement, often associated with an intraventricular hemorrhage. Doppler flow ultrasonography, if available, could help in the diagnosis. In another study newborns had a power Doppler HUS, which detected about $50 \%$ of the instances of CSVT [15]. In our case, serial HUS failed to identify the CSVT in this preterm infant. This newborn did not have white matter abnormalities or hemorrhage that could raise the suspicion of an underlying venous thrombosis and Doppler ultrasonography was not performed routinely in the particular institution. For cases like this an MRI combined with an MRV is necessary for confirmation of the diagnosis of CSVT. 


\section{Conclusion}

This was a descriptive study on the etiology, clinical presentation, management, and necessary work-up of neonatal stroke in a regional neonatal population with limited prenatal care. Our case series illustrated four different presentations of strokes in the perinatal period. While the management of most perinatal strokes is supportive, early recognition allows for the focus to be placed on treatment of underlying conditions and preventing further injury.

$\begin{array}{ll}\text { Abbreviations } \\ \text { AED: } & \text { Antiepileptic drugs } \\ \text { aPTT: } & \text { Activated partial thromboplastin time } \\ \text { CSVT: } & \text { Cerebral sinus venous thrombosis } \\ \text { CT: } & \text { Computed tomography } \\ \text { CXR: } & \text { Chest radiograph } \\ \text { EEG: } & \text { Electroencephalogram } \\ \text { ECG: } & \text { Electrocardiogram } \\ \text { FFP: } & \text { Fresh Frozen Plasma } \\ \text { GBS: } & \text { Group B Streptococcus } \\ \text { GIR: } & \text { Glucose Infusion Rate } \\ \text { GTT: } & \text { Glucose tolerance test } \\ \text { HUS: } & \text { Head ultrasound } \\ \text { IUGR: } & \text { Intrauterine growth restriction } \\ \text { IVH: } & \text { Intraventricular hemorrhage } \\ \text { KB: } & \text { Kleihauer-Betke test } \\ \text { LMWH: } & \text { Low molecular weight heparin } \\ \text { MCA: } & \text { Middle cerebral artery } \\ \text { MRI: } & \text { Magnetic resonance imaging } \\ \text { MRV: } & \text { Magnetic resonance venography } \\ \text { NICU: } & \text { Neonatal intensive care unit } \\ \text { PAIS: } & \text { Perinatal arterial ischemic stroke } \\ \text { PNC: } & \text { Prenatal care } \\ \text { PROM: } & \text { Prolonged rupture of membranes } \\ \text { RBC: } & \text { Red blood cells. } \\ & \end{array}$

\section{Competing Interests}

The authors have no conflict of interests to disclose.

\section{Authors' Contributions}

Dimitrios Angelis was the attending neonatologist who was involved in the care of the patients, participated in the concept of the article, and wrote the initial and revised drafts of the manuscript. Sonia Joseph was a medical student who wrote parts of the initial manuscript and helped to formulate the discussion. Robert Bennett was the attending neonatologist who participated in the care of the patients, reviewed and revised the manuscript, and had key contribution in the formulation of the discussion. Bhargavi Kola was an attending pediatrician who participated in the concept of the article and revised parts of the manuscript. Amanda Hughes took care of the patients as a neonatal nurse practitioner and critically revised the manuscript. All authors approved the final manuscript as submitted and agree to be accountable for all aspects of the work.

\section{References}

[1] M. A. Rutherford, L. A. Ramenghi, and F. M. Cowan, "Neonatal stroke," Archives of Disease in Childhood. Fetal and Neonatal Edition, vol. 97, no. 5, pp. F377-F384, 2012.

[2] K. C. Fitzgerald, L. S. Williams, B. P. Garg, K. S. Carvalho, and M. R. Golomb, "Cerebral sinovenous thrombosis in the neonate," Archives of Neurology, vol. 63, no. 3, pp. 405-409, 2006.

[3] J. Estan and P. Hope, "Unilateral neonatal cerebral infarction in full term infants," Archives of Disease in Childhood: Fetal and Neonatal Edition, vol. 76, no. 2, pp. F88-F93, 1997.

[4] J. M. Perlman, N. K. Rollins, and D. Evans, "Neonatal stroke: clinical characteristics and cerebral blood flow velocity measurements," Pediatric Neurology, vol. 11, no. 4, pp. 281-284, 1994.

[5] D. A. Nagey, "The content of prenatal care," Obstetrics and Gynecology, vol. 74, no. 3, part 2, pp. 516-528, 1989.

[6] C. T. Lang and J. D. Iams, "Goals and strategies for prevention of preterm birth: an obstetric perspective," Pediatric Clinics of North America, vol. 56, no. 3, pp. 537-563, 2009.

[7] R. G. Cox, L. Zhang, M. E. Zotti, and J. Graham, "Prenatal care utilization in mississippi: racial disparities and implications for unfavorable birth outcomes," Maternal and Child Health Journal, vol. 15, no. 7, pp. 931-942, 2011.

[8] J. Lee, L. A. Croen, and K. H. Backstrand, "Maternal and infant characteristics associated with perinatal arterial stroke in the infant," JAMA, vol. 293, no. 6, pp. 723-729, 2005.

[9] F. T. Kraus and V. I. Acheen, "Fetal thrombotic vasculopathy in the placenta: cerebral thrombi and infarcts, coagulopathies, and cerebral palsy," Human Pathology, vol. 30, no. 7, pp. 759-769, 1999.

[10] Y. W. Wu, S. P. Miller, K. Chin et al., "Multiple risk factors in neonatal sinovenous thrombosis," Neurology, vol. 59, no. 3, pp. 438-440, 2002.

[11] F. J. Berfelo, K. J. Kersbergen, C. H. Van Ommen et al., "Neonatal cerebral sinovenous thrombosis from symptom to outcome," Stroke, vol. 41, no. 7, pp. 1382-1388, 2010.

[12] M. J. N. L. Benders, F. Groenendaal, C. S. P. M. Uiterwaal et al., "Maternal and infant characteristics associated with perinatal arterial stroke in the preterm infant," Stroke, vol. 38, no. 6, pp. 1759-1765, 2007.

[13] M. J. Benders, F. Groenendaal, C. S. Uiterwaal, and L. S. de Vries, "Perinatal arterial stroke in the preterm infant," Seminars in Perinatology, vol. 32, no. 5, pp. 344-349, 2008.

[14] A. Plaisier, M. M. Raets, G. M. Ecury-Goossen et al., "Serial cranial ultrasonography or early MRI for detecting preterm brain injury?" Archives of Disease in Childhood. Fetal and Neonatal Edition, vol. 100, no. 4, pp. F293-F300, 2015.

[15] S. Grunt, K. Wingeier, E. Wehrli et al., "Cerebral sinus venous thrombosis in Swiss children," Developmental Medicine and Child Neurology, vol. 52, no. 12, pp. 1145-1150, 2010. 


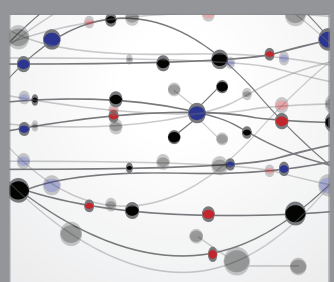

The Scientific World Journal
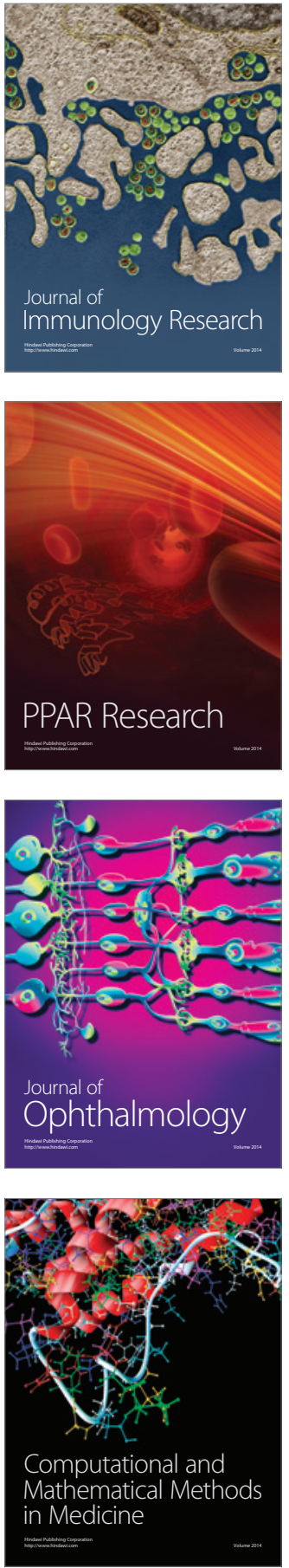

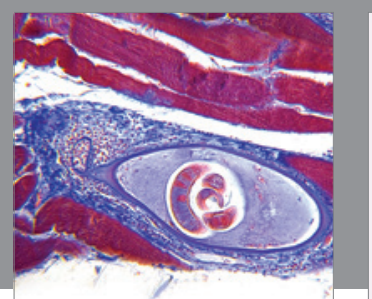

Gastroenterology Research and Practice
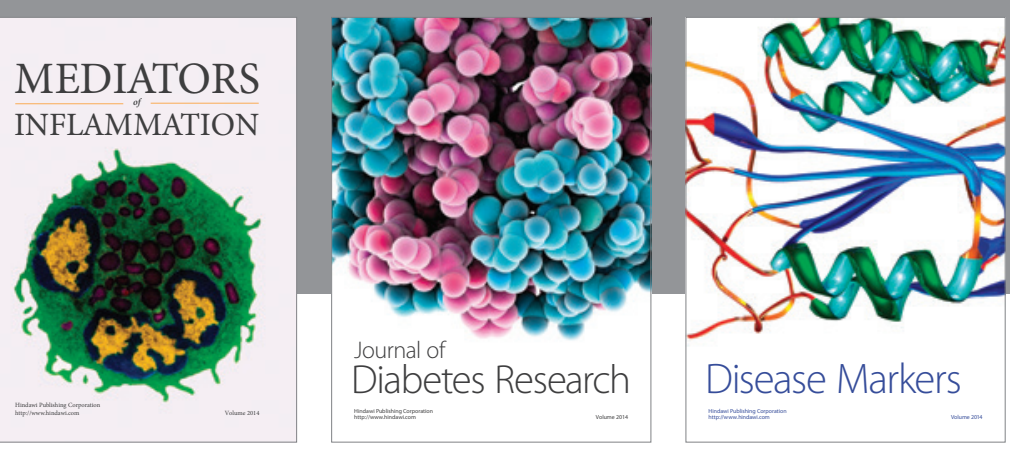

Disease Markers

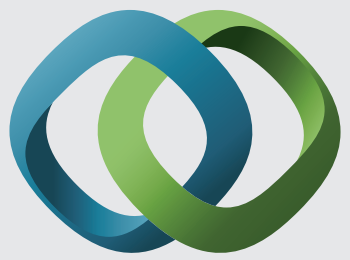

\section{Hindawi}

Submit your manuscripts at

https://www.hindawi.com
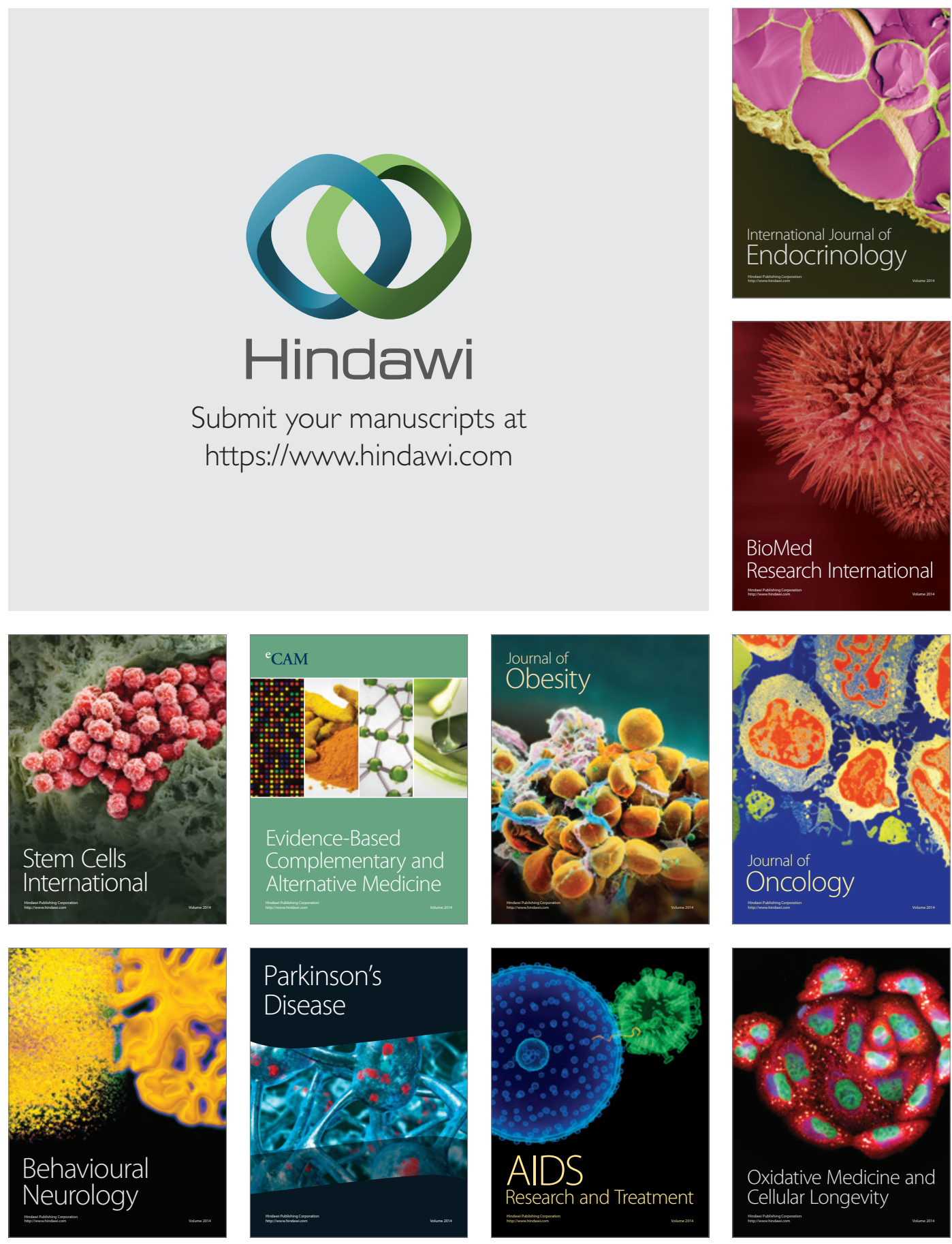